\title{
CORRELAÇÕES ENTRE OS ELEMENTOS METEOROLÓGICOS E AS OCORRÊNCIAS DE INCÊNDIOS FLORESTAIS NA ÁREA URBANA DE JUIZ DE FORA, MG ${ }^{1}$
}

Fillipe Tamiozzo Pereira Torres², Guido Assunção Ribeiro ${ }^{3}$, Sebastião Venâncio Martins ${ }^{3}$ e Gumercindo Souza $\operatorname{Lima}^{3}$

\begin{abstract}
RESUMO - Os incêndios florestais no Brasil tornam-se a cada ano mais críticos, com o aumento da extensão da área queimada e os consequentes danos ao ambiente e à sociedade. A ocorrência e propagação dos incêndios florestais estão fortemente associadas às condições climáticas ou fatores climáticos. Entre as influências que o clima pode exercer sobre as ocorrências, destaca-se a distribuição do conteúdo de umidade da vegetação morta, que constitui o principal combustível dos incêndios. O objetivo deste estudo foi comparar o índice de correlação entre os fatores meteorológicos e as ocorrências de incêndios florestais dentro da área urbana do Município de Juiz de Fora. Para a sua realização foi utilizada uma série temporal abrangendo o período de 1995 a 2004. De acordo com os resultados, a umidade relativa do ar foi o elemento que mais se correlacionou com as ocorrências. A precipitação e a diferença entre precipitação e evaporação mostraram-se mais correlacionadas com os incêndios quando analisadas a sua acumulação dentro de um período de 10 dias antes de cada ocorrência. A utilização de elementos isolados apresentou baixa correlação com os incêndios, evidenciando a utilização de modelos que agrupem os elementos climáticos para a predição das ocorrências.
\end{abstract}

Palavras-chave: Clima, Correlação e Fogo.

\section{CORRELATIONS BETWEEN THE METEOROLOGICAL ELEMENTS AND THE OCCURRENCES OF FOREST FIRES IN THE URBAN AREA OF JUIZ DE FORA, MG}

\begin{abstract}
Forest fires in Brazil become more critical every year, with the increase of the extension of burned areas and the consequent damages to the atmosphere and society. The occurrence and propagation of forest fires are strongly associated with climatic factors or conditions. Among the influences that the climate can exercise on the occurrences is the distribution of dead vegetation humidity, which constitutes the main fuel of fires. The objective of this study was to compare the correlation index between the meteorological factors and the occurrences of forest fires in the urban area of the district of Juiz de Fora. To accomplish the study, a temporary series was used, including the period from 1995 to 2004. According to the results, the relative humidity of the air was the element that showed most correlation with the occurrences. The precipitation and the difference between precipitation and evaporation showed more correlation with the fires when analyzing its accumulation within the period of 10 days before each occurrence. The use of isolated elements presented a low correlation with the fires, suggesting the use of models containing climatic elements for the prediction of the occurrences.
\end{abstract}

Keywords: Climate, Correlation and Fire.

\footnotetext{
${ }^{1}$ Recebido em 25.04.2009 e aceito para publicação em 25.08.2010.

${ }^{2}$ Prefeitura Municipal de Ubá, PMU, Brasil. E-mail: <torresftp@yahoo.com.br>.

${ }^{3}$ Universidade Federal de Viçosa, UFV, Brasil. E-mail: <gribeiro@ufv.br>.
} 


\section{INTRODUÇÃO}

Os incêndios florestais, em âmbito global, podem causar severas perdas à biodiversidade, ao ciclo hidrológico e ao ciclo do carbono na atmosfera, diminuindo os serviços ambientais que a floresta, mantida em seu padrão atual, poderia proporcionar ao Planeta (SILVA et al., 2003).

Para Fiedler et al. (2006), os incêndios florestais geram diversos prejuízos econômicos, paisagísticos e ecológicos, podendo ocorrer em unidades de conservação, áreas de preservação, fazendas, margens de estradas, proximidades de aglomerados urbanos e áreas de reflorestamento, entre outras localidades.

Soares (1992), em estudo para traçar o perfil dos incêndios florestais no Brasil, agrupou as principais causas em queima para limpeza, que corresponde a $63,7 \%$ da área queimada, seguida da queima criminosa ou provocada por incendiários $(14,7 \%)$, fogos de recreação ou acidental $(11,6 \%)$, diversos $(4,4 \%)$, fumantes $(2,9 \%)$, estradas de ferro $(0,5 \%)$ e queimas de origem natural ou provocadas por raios, que correspondem a apenas $0,2 \%$.

Existem dois tipos de fatores determinantes do grau de perigo de incêndio: os fatores constantes, representados pelo tipo de material combustível, o qual envolve os diferentes tipos de floresta e o relevo e os fatores variáveis, representados principalmente pela umidade do material combustível e as condições climáticas como a velocidade e direção do vento, a umidade relativa, a temperatura, o ponto de orvalho, a precipitação e a instabilidade atmosférica (NUNES, 2005).

Nunes et al. (2006) afirmaram, ainda, que não somente a ocorrência, mas também a propagação dos incêndios florestais estão fortemente associados às condições climáticas ou fatores climáticos. A intensidade de um incêndio e a velocidade com que ele avança estão diretamente ligados à umidade relativa, à temperatura do ar e à precipitação.

A possibilidade de ocorrência, bem como a frequência dos incêndios florestais, está relacionada às condições atmosféricas locais, conforme discutido por Soares (1984). Dessa forma, o conhecimento das variáveis meteorológicas é um passo importante para a elaboração de programas de prevenção e de combate aos incêndios florestais. A partir da análise climática é possível determinar os períodos de maior probabilidade de ocorrências, facilitando a adoção de medidas de prevenção, a estimativa da logística para o combate e estimativa de danos causados pelo fogo ao ambiente.

O objetivo deste trabalho foi analisar os elementos climáticos que mais se relacionam com as ocorrências de incêndios florestais, bem como o comportamento acumulativo desses elementos em relação à quantidade de ocorrências.

\section{MATERIAL E MÉTODOS}

O estudo foi realizado a partir de uma série temporal abrangendo o período entre 1995 e 2004. Os dados meteorológicos foram obtidos no Laboratório de Climatologia e Análise Ambiental (LabCAA) da Universidade Federal de Juiz de Fora (UFJF). Os dados das ocorrências de incêndios, dentro da área urbana do município, foram fornecidos pelo $4^{\circ}$ Batalhão de Bombeiros Militares ( $4^{\circ}$ B.B.M.).

O Município de Juiz de Fora apresenta, de acordo com o IBGE (2000), uma população de 456.432 habitantes. Localiza-se no Sudeste do Estado de Minas Gerais, estando o centro da cidade localizado nas coordenadas $21^{\circ} 41^{\prime} 20^{\prime \prime} \mathrm{S}$ e $43^{\circ} 20^{\prime} 40^{\prime \prime} \mathrm{W}$ (PJF, 1996). O clima, de acordo com Köeppen, é do tipo Cwb (tropical de altitude), com chuvas concentradas no período de outubro a abril e estação mais seca de maio a setembro.

Para a realização deste estudo foram utilizados os dados das 3.118 ocorrências de incêndios florestais e os valores referentes aos elementos meteorológicos umidade relativa do ar média (UR média), umidade relativa do ar das 13 e das 15 h (UR ${ }_{13}$ e UR ${ }_{15}$ ), velocidade do vento (vento m/s), precipitação, evaporação, insolação, temperatura do ar média ( $\mathrm{T}^{\circ} \mathrm{C}$ média) e temperaturas do ar medidas às 13 e às $15 \mathrm{~h}\left(\mathrm{~T}^{\circ} \mathrm{C}\right.$ e $\mathrm{T}^{\circ} \mathrm{C}_{15}$ ) de todos os dias da série (1995 - 2004).

A partir das variáveis disponíveis foram construídas as seguintes variáveis:

- Média da umidade relativa do ar de dias anteriores a cada dia da série, nas seguintes situações: véspera (UR média1), de dois dias (UR média2), três dias (UR média3), quatro dias (UR média4), cinco dias (UR média5) e 10 dias (UR média 10).

- Precipitação total diária de dias anteriores a cada dia da série, nas seguintes situações: da véspera (Precipitação 1), de dois dias (Precipitação 2), três dias (Precipitação 3), quatro dias (Precipitação 4), cinco dias (Precipitação 5) e 10 dias (Precipitação 10). 
- Diferença entre a precipitação e a evaporação do dia (P-EVAP) de dias anteriores a cada dia da série, nas seguintes situações: véspera (P-EVAP1), dois dias (P-EVAP2), três dias (P-EVAP3), quatro dias (P-EVAP4), cinco dias (P-EVAP5) e 10 dias (P-EVAP 10).

- Evaporação total diária de dias anteriores a cada dia da série, nas seguintes situações: na véspera (Evaporação 1), dois dias (Evaporação 2), três dias (Evaporação 3), quatro dias (Evaporação 4), cinco dias (Evaporação 5) e 10 dias (Evaporação 10).

- Insolação total diária de dias anteriores a cada dia da série, nas seguintes situações: na véspera (Insolação 1), dois dias (Insolação 2), três dias (Insolação 3), quatro dias (Insolação 4), cinco dias (Insolação 5) e 10 dias (Insolação 10).

- Temperatura do ponto de orvalho de cada dia da série.

Em condições normais, a temperatura do ponto de orvalho é uma temperatura crítica entre o estado de vapor e a condensação d'água na atmosfera, ou seja, acima dela a água mantém-se na forma de vapor, e abaixo ela, passa gradativamente à fase líquida. É determinada pela seguinte equação:

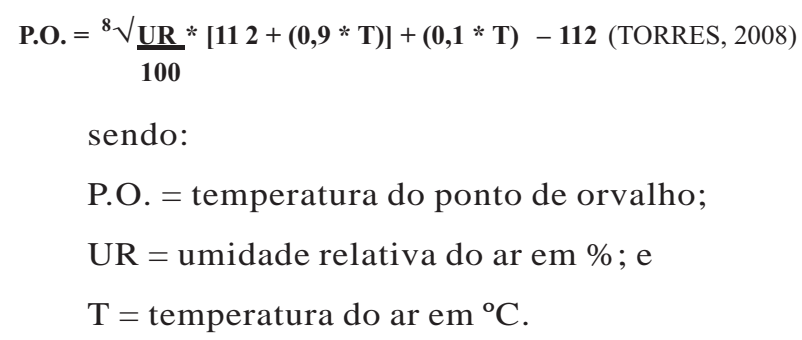

- Pressão real de vapor de cada dia da série.

A pressão de vapor da água é a componente da pressão total contribuída pelo vapor de água. É determinada pela equação:

$\mathbf{e}=\mathbf{E}^{\prime} \mathbf{-} \mathbf{C} \mathbf{P z}\left(\mathbf{T}-\mathbf{T}^{\prime}\right)($ TORRES, 2008)

sendo:

e = pressão real de vapor, em mmHg;

$\mathrm{E}^{\prime}$ = pressão máxima de vapor d’água para a temperatura $\mathrm{T}^{\prime}$;

$\mathrm{C}=$ constante psicrométrica: $\mathrm{C}=0,0008 \mathrm{sem}$ ventilação forçada; $C=0,0006$ com ventilação;

$$
\begin{aligned}
& \mathrm{Pz}=\text { pressão atmosférica em mmHg; } \\
& \mathrm{T}=\text { temperatura do ar (bulbo seco) em }{ }^{\circ} \mathrm{C} \text {; e } \\
& \mathrm{T}^{\prime}=\text { temperatura do bulbo úmido em }{ }^{\circ} \mathrm{C} .
\end{aligned}
$$

- Pressão de saturação de cada dia da série.

Pressão de saturação de vapor é a pressão parcial de vapor d'água na condição de saturação. É definida pela equação:

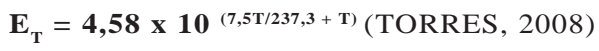

sendo:

$\mathrm{E}_{\mathrm{T}}=$ pressão máxima de vapor d’água na temperatura T, em mmHg; e

$\mathrm{T}=$ temperatura do ar em ${ }^{\circ} \mathrm{C}$.

- Déficit de saturação de cada dia da série.

O déficit de saturação do ar é igual a diferença entre a pressão máxima de vapor d’água e a pressão real de vapor d’água, podendo ser calculado através da seguinte expressão:

$$
\mathbf{d}=\mathbf{E}(\mathbf{1}-\mathbf{H} / \mathbf{1 0 0})(\mathrm{TORRES}, 2008)
$$

sendo:

d = déficit de saturação do ar em milibares;

E = pressão máxima de vapor d’água em milibares; e

$\mathrm{H}=$ umidade relativa do ar em \%.

Para analisar a correlação entre os elementos meteorológicos e as ocorrências de incêndios florestais foi determinado o Coeficiente de Correlação Linear de Pearson (r), através do software Statistica 7 (StatSoft) para cada um em relação ao número de ocorrências da série estudada.

\section{RESULTADOS}

A Tabela 1 mostra que a correlação entre a variável resposta e suas preditoras dos dados diários é fraca. A variável explicativa que mais se correlaciona com o número de ocorrências é a umidade relativa medida às $15 \mathrm{~h}\left(\mathrm{UR}_{15}\right)$, em que se obteve correlação $\mathrm{r}=-0,4843$, e a menor foi a velocidade do vento, a única variável não significativa.

Revista Árvore, Viçosa-MG, v.35, n.1, p.143-150, 2011 
Tabela 1 - Correlação linear de Pearson (r) entre o número de ocorrências de incêndios e as variáveis estudadas no período de 1995-2004.

Table 1 - Lineal correlation of Pearson $(r)$ between the number of occurrences of fires and the variables studied in the period of 1995-2004.

\begin{tabular}{|c|c|c|c|}
\hline Elementos & $\mathrm{r}^{*}$ & Elementos & $\mathrm{r}^{*}$ \\
\hline $\mathrm{UR}_{15}$ & -0.4843 & Déficit de Saturação & 0.4446 \\
\hline $\mathrm{UR}_{13}$ & -0.4732 & Evaporação & 0.4056 \\
\hline UR média & -0.4671 & Insolação & 0.3578 \\
\hline UR média1 & -0.4324 & Evaporação2 & 0.3555 \\
\hline UR média2 & -0.4231 & Evaporação3 & 0.3527 \\
\hline UR média3 & -0.4131 & Evaporação4 & 0.3452 \\
\hline UR média4 & -0.4034 & Insolação4 & 0.3451 \\
\hline UR média5 & -0.392 & Insolação5 & 0.3446 \\
\hline Ponto de Orvalho & -0.3567 & Insolação10 & 0.3429 \\
\hline Pressão Real & -0.3554 & Evaporação5 & 0.341 \\
\hline UR média10 & -0.3417 & Insolação3 & 0.3404 \\
\hline Precipitação10 & -0.3049 & Insolação2 & 0.3288 \\
\hline P-EVAP10 & -0.2936 & Evaporação1 & 0.3216 \\
\hline Precipitação5 & -0.2821 & Evaporação10 & 0.3148 \\
\hline Precipitação4 & -0.2743 & Insolação1 & 0.3038 \\
\hline Precipitação3 & -0.2598 & $\mathrm{~T}^{\circ} \mathrm{C}_{15}$ & 0.1829 \\
\hline Precipitação2 & -0.2397 & Pressão de Saturação & 0.1814 \\
\hline P-EVAP5 & -0.2115 & $\mathrm{~T}^{\circ} \mathrm{C}_{13}$ & 0.1326 \\
\hline P-EVAP4 & -0.201 & $\mathrm{~T}^{\circ} \mathrm{C}$ média & 0.0432 \\
\hline Precipitação & -0.1999 & & \\
\hline P-EVAP3 & -0.1934 & & \\
\hline Precipitação1 & -0.1913 & & \\
\hline P-EVAP2 & -0.174 & & \\
\hline P-EVAP1 & -0.1411 & & \\
\hline P-EVAP & -0.1291 & & \\
\hline Vento m/s & -0.0115 n.s. & & \\
\hline
\end{tabular}

Os valores de "r" quando negativos significam que, quanto menor for o valor do elemento climático, maiores serão as chances de ocorrências, no entanto, se o valor de " $r$ " for positivo, quanto maior o valor do elemento climático, maior a probabilidade de ocorrências de incêndios.

Os dados de umidade relativa e da temperatura quando medidos às $15 \mathrm{~h}\left(\mathrm{UR}_{15}\right.$ e $\left.\mathrm{T}^{\circ} \mathrm{C}_{15}\right)$ têm maior coeficiente de correlação em relação aos valores médios (UR média e $\mathrm{T}^{\circ} \mathrm{C}$ média) e em relação aos mensurados às $13 \mathrm{~h}\left(\mathrm{UR}_{13} \mathrm{e} \mathrm{T}^{\circ} \mathrm{C}_{13}\right)$. Os dados de precipitação e P-EVAP têm maior correlação quando acumulados, enquanto UR, evaporação e insolação são mais eficientes quando analisados no dia da ocorrência.

Conforme a Tabela 2, a quantidade de ocorrências está intimamente relacionada à quantidade de precipitação no dia da ocorrência, e 97\% dos incêndios ocorreram em dias com precipitação menor que $3 \mathrm{~mm}$. Contudo, a porcentagem de dias com ocorrências melhor se relaciona com o acúmulo da precipitação, em que em $79 \%$ dos dias sem chuva nos cinco dias anteriores ocorreram incêndios.

Nos 52\% dos dias com precipitação menor que $3 \mathrm{~mm}$ (Tabela 2), que concentram 97\% do total de ocorrências, há diferença entre outros elementos climáticos em relação aos $48 \%$ desses dias sem ocorrências. Quando o índice de precipitação foi menor que 3 mm (Tabela 3), as variáveis temperatura das 15 h, evaporação e insolação foram superiores, enquanto a umidade relativa do ar das $15 \mathrm{~h}$ foi inferior nos dias em que houver incêndios comparados com os dias sem ocorrências. A mesma tendência de aumento das três primeiras variáveis e de diminuição da $U_{15}$ é observada à medida que vão aumentando o número de ocorrências por dia, ampliando a diferença entre os valores das variáveis em relação aos dias sem ocorrência.

Com relação à umidade relativa do ar medida às 15 h (Tabela 4), em todos os dias do período estudado em que a umidade relativa foi inferior a $36 \%$ ocorreram 
Tabela 2 - Porcentagem de ocorrências e de dias com ocorrências de acordo com a quantidade e o acúmulo de precipitação no período de 1995-2004..

Table 2 - Percentage of occurrences and of days with occurrences in agreement with the amount and the precipitation accumulation, in the period of 1995-2004.

\begin{tabular}{|c|c|c|c|c|c|c|c|c|}
\hline \multirow{2}{*}{$\begin{array}{l}\text { Precipitação } \\
\text { acumulada }\end{array}$} & \multicolumn{2}{|c|}{$<3 \mathrm{~mm}$} & \multicolumn{2}{|c|}{$<2 \mathrm{~mm}$} & \multicolumn{2}{|c|}{$<1 \mathrm{~mm}$} & \multicolumn{2}{|c|}{$0 \mathrm{~mm}$} \\
\hline & Ocor\% & Dias\% & Ocor\% & Dias\% & Ocor\% & Dias\% & Ocor\% & Dias\% \\
\hline no dia & 97 & 52 & 97 & 53 & 95 & 56 & 93 & 57 \\
\hline na véspera & 93 & 56 & 93 & 59 & 90 & 63 & 87 & 65 \\
\hline em 2 dias & 90 & 62 & 90 & 64 & 86 & 69 & 81 & 71 \\
\hline em 3 dias & 85 & 66 & 84 & 68 & 80 & 72 & 74 & 74 \\
\hline em 4 dias & 81 & 69 & 80 & 71 & 75 & 75 & 68 & 77 \\
\hline em 5 dias & 77 & 72 & 76 & 74 & 68 & 78 & 61 & 79 \\
\hline em 10 dias & 60 & 73 & 59 & 76 & 44 & 75 & 37 & 77 \\
\hline
\end{tabular}

Tabela 3 - Valores médios dos elementos climáticos nos dias sem ocorrência de incêndios e nos dias com uma ou mais ocorrências quando a precipitação acumulada foi menor que 3 mm, no período de 1995-2004..

Table 3 - Medium values of the climatic elements in the days without occurrence of fires and in days with an or more occurrences when the accumulated precipitation was smaller than $3 \mathrm{~mm}$, in the period of 1995-2004.

\begin{tabular}{lcccc}
\hline Dias com precipitação $<3 \mathrm{~mm}$ & \multicolumn{3}{c}{ Média } \\
\cline { 2 - 5 } & $\mathrm{T}^{\mathrm{o}} \mathrm{C}_{15}$ & Evaporação & Insolação & UR\% \\
\hline Dias sem ocorrências & 23 & 3 & 5 & 69.0 \\
Dias com ocorrências & 24 & 4 & 7 & 57.0 \\
Dias com 1 ocorrência & 23 & 3 & 6 & 62.0 \\
Dias com 2 ocorrências & 24 & 4 & 7 & 59.0 \\
Dias com 3 ocorrências & 25 & 5 & 8 & 55.0 \\
Dias com mais de 4 ocorrências & 25 & 8 & 50.0 \\
\hline
\end{tabular}

incêndios. Nesse período, a média de ocorrências por dia foi de 6,4 , concentrando $12 \%$ de todas elas. A maior parte das ocorrências (91\%) ocorreu quando a umidade foi inferior a $70 \%$, e $57 \%$ desses dias apresentaram média de 1.7 ocorrência por dia. No entanto, acima de $70 \%$ de umidade a média de ocorrências por dia foi de 0,27 , apresentando $14 \%$ de dias com ocorrência e concentrando apenas $8 \%$ do total de ocorrências.

Tabela 4 - Porcentagem de ocorrências, porcentagem de dias com ocorrências e número de ocorrências por dia de acordo com a umidade relativa do ar das $15 \mathrm{~h}$, no período de 1995-2004.

Table 4-Percentage of occurrences, percentage of days with occurrences and number of occurrences a day in agreement with the relative humidity of the air of 15:00 o'clock, in the period of 1995-2004.

\begin{tabular}{cccc}
\hline UR\% & Ocorrências\% & $\begin{array}{c}\text { \% de dias } \\
\text { com ocorrências }\end{array}$ & $\begin{array}{c}\text { Ocorrências } \\
\text { por dia }\end{array}$ \\
\hline$>90$ & $<1$ & $4 \%$ & 0.1 \\
$>80$ & 3 & 9 & 0.22 \\
$>70$ & 8 & 14 & 0.27 \\
$<70$ & 91 & 57 & 1.7 \\
$<60$ & 68 & 70 & 2.4 \\
$<50$ & 38 & 80 & 3.8 \\
$<40$ & 17 & 89 & 5.8 \\
$<36$ & 12 & 100 & 6.4 \\
\hline
\end{tabular}

Os resultados indicaram que 96\% das ocorrências (Tabela 5) foram observadas em dias em que a evaporação foi maior que a precipitação, e 54\% dos dias nessa condição apresentaram pelo menos um incêndio. No entanto, quando P-EVAP acumulada em 10 dias anteriores foi negativo (evaporação > precipitação), 64\% dos dias apresentaram pelo menos uma ocorrência concentrando 83\% de todas as ocorrências nesse período.

Tabela 5-Porcentagem de ocorrências e de dias com ocorrências de acordo com a diferença entre precipitação e evaporação(P-EVAP) negativa acumulada no período de 1995-2004.

Table 5-Percentage of occurrences and of days with occurrences in agreement with the difference between precipitation and evaporation ( $P$-EVAP) accumulated negative, in the period of 1995-2004.

\begin{tabular}{ccc}
\hline $\begin{array}{c}\text { P-EVAP } \\
\text { (negativo acumulado) }\end{array}$ & Ocorrências\% & Dias \% \\
\hline no dia & 96 & 54 \\
na véspera & 95 & 57 \\
em 2 dias & 93 & 58 \\
em 3 dias & 91 & 60 \\
em 4 dias & 89 & 60 \\
em 5 dias & 88 & 61 \\
em 10 dias & 83 & 64 \\
\hline
\end{tabular}




\section{DISCUSSÃO}

A correlação linear de Pearson (r) entre o número de ocorrências de incêndios e as variáveis estudadas no período de 1995-2004 encontrada neste trabalho foi similar à encontrada por Soares e Paez (1972) na região centro paranaense. Esses autores verificaram correlações importantes, sobretudo entre a umidade relativa e o déficit de saturação e baixa correlação da temperatura do ar.

A não significância da velocidade do vento pode ser explicada pelo período de maior movimentação vertical e horizontal do ar que se concentra no verão, estação de menor número de incêndios, entretanto o inverno, caracterizado por menores velocidades do vento, apresenta maior concentração de ocorrências. O mesmo acontece com os coeficientes mais baixos das temperaturas (média, das 13 e das 15 h), a variação sazonal delas tende a mascarar sua relação com o fenômeno. Essa situação também foi observada por Jacobi (2007), que encontrou baixa correlação entre temperatura e velocidade do vento com o número de ocorrências.

Os resultados não implicam insignificância da velocidade do vento ou da temperatura sobre os incêndios e, sim, que para analisar sua influência se devem buscar métodos mais adequados de análise.

Por volta das 15 h é o período em que se observa o maior valor da temperatura diária, obtendo com isso o menor valor diário da umidade relativa do ar, favorecendo o maior número de ocorrências nesse horário. O mesmo resultado não foi compartilhado por Jacobi (2007), que em estudo sobre as ocorrências de incêndios florestais em Santa Maria, RS, encontrou coeficiente maior de UR média $(-0,41)$ em comparação com a da $\operatorname{UR}_{15}(0,32)$, mostrando variações no comportamento dos incêndios de acordo com as características da área estudada.

Os dados apontam, ainda, para a importância da influência dos elementos meteorológicos sobre a umidade do material combustível. De acordo com Nunes et al. (2005), a umidade do material combustível expressa a porcentagem de água que ele contém, em relação ao seu peso seco. A primeira influência da umidade na combustão do material florestal é a necessidade da grande quantidade de energia requerida para transformar em vapor a água existente no combustível. Isso representa redução na quantidade de calor disponível para a combustão propriamente dita. A UR, déficit de saturação, evaporação e insolação atuam diretamente sobre a quantidade de umidade no combustível e estão entre os maiores índices de correlação.

Nunes et al. (2005) afirmaram ainda que a umidade atmosférica é elemento decisivo nos incêndios florestais, tendo efeito direto na inflamabilidade dos combustíveis florestais, havendo troca constante de umidade entre a atmosfera e os combustíveis mortos. O material seco absorve água de uma atmosfera úmida e a libera quando o ar está seco. A quantidade de umidade que o material morto pode absorver e reter do ar depende, basicamente, da umidade relativa do ar. Quanto mais seco o ar, maior a perda de umidade pelo combustível, favorecendo as ocorrências (Tabela 4). Durante períodos extremamente secos, a baixa umidade pode, inclusive, afetar o conteúdo de umidade do material vivo.

O déficit de saturação é a diferença entre a quantidade máxima de vapor d'água que o ar comporta e a quantidade de vapor no ar, e quando maior a diferença, maior o déficit, ou seja, torna-se possível maior evaporação visto que a quantidade de vapor contido no ar está abaixo do que ele comporta, no entanto quando a diferença é pequena ela dificulta a formação de vapor d’água, já que a quantidade de vapor está próxima ao limite máximo de vapor comportado pelo ar, mantendo o combustível úmido por mais tempo, o que dificulta sua combustão.

A evaporação influi no grau de secagem do combustível, já que ela significa a perda de umidade pelo vegetal. Quanto maior for a evaporação, maior e mais rápida será a secagem do material, e consequentemente, maior o perigo de fogo.

A intensidade da insolação está intimamente ligada à umidade do ar, visto que este, quando mais seco, menor a quantidade de nuvens formadas. A insolação está ligada também à radiação do Sol, e quanto maior o tempo exposto à luz solar, maior o tempo de exposição à sua radiação. De acordo com Couto e Cândido (1980), a exposição do combustível à insolação provoca a evaporação, acelerando sua secagem.

A maior correlação dos dados, quando acumulados, de precipitação e P-EVAP está relacionada ao tempo de resposta do ambiente às condições atmosféricas. Os valores da precipitação, de acordo com Sampaio (1991), não interferem imediatamente na probabilidade 
de ocorrências de incêndios, sendo necessário intervalo maior de tempo para a observação de sua influência. Isso ocorre porque, no início do período de escassez pluviométrica, o solo ainda mantém certa umidade, que é transferida gradualmente para o combustível. Entretanto no final do período de escassez, com as primeiras chuvas, é necessário tempo hábil para a absorção dessa umidade pelo sistema, sendo observados incêndios ainda no início do período chuvoso. Observa-se, com isso, que existe aumento da porcentagem de dias com ocorrências à medida que aumenta o período sem precipitação (Tabela 2) ou em que a evaporação é maior que a precipitação (Tabela 5).

O aumento no número de ocorrências nos dias de baixa precipitação, porém com valores mais elevados de insolação, temperatura e evaporação e menor umidade relativa do ar (Tabela 3), demonstra maior influência de um conjunto de elementos do que de um elemento isolado com o número de incêndios, evidenciando a necessidade de modelos preditivos com maior número de variáveis.

O fato de o percentual de ocorrência ter diminuído para 83\% no acumulado negativo (P-EVAP), no período de 10 dias observado na Tabela 5 é explicado pela eventual ocorrência de precipitação no período, o que dificulta o surgimento de qualquer foco de fogo. Entretanto, o aumento da porcentagem de dias com pelo menos uma ocorrência é explicado pelo acúmulo de perda de umidade, em que, quanto maior a sequência temporal em que a evaporação é maior do que a precipitação, maior a formação de material seco, favorecendo as ocorrências.

\section{CONCLUSÕES}

De acordo com os resultados, pode-se concluir que:

-Aumidade relativa do ar foi o elemento meteorológico que melhor se correlacionou com as ocorrências de incêndios florestais no Município de Juiz de Fora.

- A temperatura e a umidade medidas às $15 \mathrm{~h}$ melhor se correlacionaram com o número de incêndios do que valores médios diários e os medidos às 13 h.

- A quantidade de ocorrências em dias com precipitação inferior a $3 \mathrm{~mm}$ ou que não houve chuvas nos últimos cinco dias aumentou à medida que houve incremento da temperatura, da insolação e da evaporação e diminuição da umidade relativa do ar.
- Noventa e seis por cento dos incêndios ocorreram em dias em que a evaporação foi maior que a precipitação e quanto mais dias não se observava precipitação, maior foi o percentual de dias com pelo menos uma ocorrência.

- Os baixos índices de correlação entre as ocorrências de incêndios e os elementos meteorológicos indicaram a necessidade de incorporar mais de uma variável nos modelos preditivos, principalmente em se tratando de ambiente urbano que apresenta dinâmica de microclima diferente de ambientes rurais.

- A influência da velocidade do vento e da temperatura sobre as ocorrências não se mostrou eficaz isoladamente através da correlação linear, sugerindo estudos mais detalhados por meio da combinação de uma ou mais variáveis.

\section{REFERÊNCIAS}

FIEDLER, N. C. et al. Avaliação das condições de trabalho, treinamento, saúde e segurança de brigadistas de combate a incêndios florestais em unidades de conservação do Distrito Federal: estudo de caso. Viçosa: Revista Árvore, v.30, n.1, p.55-63, 2006.

\section{INSTITUTO BRASILEIRO DE GEOGRAFIA E ESTATÍSTICA - IBGE. Censo Demográfico 2000. Rio de Janeiro: 2000.}

JACOBI, L. F. Queimadas acidentais em campo em Santa Maria - RS. 2007. $57 \mathrm{f}$. Tese (Doutorado em Agronomia) - Universidade Federal de Santa Maria, Santa Maria, 2007.

NUNES, J. R. S. FMA+ - Um novo índice de perigo de incêndios florestais para o Estado do Paraná - Brasil. 2005. 150 f. Tese (Doutorado em Engenharia Florestal) Universidade Federal do Paraná, Curitiba, 2005.

NUNES, J. R. S. et al. Estimativa da umidade relativa das 13:00 h, com base nos dados das 9:00 h e das 15:00 h, para o Estado do Paraná.

Floresta, v.35, n.2, p.247-258, 2005.

NUNES, J. R. S. et al. Especificação de um sistema computacional integrado de controle de incêndios florestais. Floresta, v.36, n.2, p.201-211, 2006.

PREFEITURA DE JUIZ DE FORA. Plano Diretor de Juiz de Fora. Juiz de Fora: Concorde, 1996.

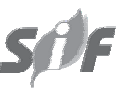

Revista Árvore, Viçosa-MG, v.35, n.1, p.143-150, 2011 
SAMPAIO, O. B. Estudo comparativo de índices, para previsão de incêndios florestais, na região de Coronel Fabriciano, Minas Gerais. 1991. 88f. Dissertação (Mestrado em Ciência Florestal) Universidade Federal de Viçosa, Viçosa, MG, 1991.

SILVA, J. C. et al. Avaliação de brigadas de incêndios florestais em unidades de conservação. Revista Árvore, v.27, n.1, p.95-101, 2003.

SOARES, R. V. Prevenção e controle de incêndios florestais. Brasília: ABEAS, 1984. 120p.
SOARES, R. V. Ocorrência de incêndios em povoamentos florestais. Floresta, v.22, n.1-2, p.39-54, 1992.

SOARES, R. V.; PAEZ, G. Correlações entre alguns fatores meteorológicos e ocorrências de incêndios florestais na região Centro Paranaense.

Floresta, v.4, n.2, p.58-67, 1972.

TORRES, F. T. P. Análise da ocorrência de incêndios em vegetação na área urbana de Juiz de Fora, MG. 2008. 65p. Dissertação (Mestrado em Ciência Florestal) Universidade Federal de Viçosa, Viçosa, MG, 2008. 